\title{
O ensino por investigação na escola do campo: uma relação entre as plantas medicinais e saúde
}

\author{
Inquiry-based learning in rural schools: a relationship between \\ medicinal plants and health
}

\author{
Maíra Gaigher Zetóles (maira_gaigher@hotmail.com) \\ Universidade Federal do Espírito Santo (UFES)/PPGMPE
}

\section{Patricia Silveira da Silva Trazzi (patriciatrazzi.ufes@gmail.com) \\ Universidade Federal do Espírito Santo (UFES)/PPGMPE}

\begin{abstract}
Resumo: Neste artigo buscamos descrever a construção de uma atividade investigativa com o Tema Gerador "A saúde" realizada junto a uma turma do $6^{\circ}$ ano do Ensino Fundamental de uma escola agrícola do Estado do Espírito Santo que tem a "Pedagogia da Alternância" como princípio educativo. A pesquisa, de cunho qualitativo, contou com o aporte metodológico da pesquisa participante. O processo de produção de dados ocorreu por meio de observações da professora pesquisadora com registro em diário de campo e material escrito produzido pelos estudantes. Os dados foram analisados a partir dos pressupostos do ensino por investigação. Como resultados, observamos que a atividade promoveu o engajamento dos educandos em uma investigação propiciando um maior aprofundamento sobre as plantas medicinais.
\end{abstract}

Palavras Chave: Ensino por investigação; Educação do Campo; Ensino de Ciências

Abstract: In this article we seek to describe the construction of an investigative activity with the Generating Theme "A Saúde" carried out together with a class of the 6th year of Elementary Education of an agricultural school in the State of Espírito Santo that has the "Pedagogy of Alternation" as an educational principle. The research, of qualitative nature, relied on the methodological contribution of the participant research. The data production process took place through the observations of the researcher teacher, recorded in a field diary and written material produced by the students. The data were analyzed based on the assumptions of inquiry-based learnig. As a result, we observed that the activity promoted the students' engagement in an investigation, providing a deeper understanding of medicinal plants.

Keywords: Inquiry-Based Learning; Field Education; Science Teaching.

\section{INTRODUÇÃO}

Neste artigo buscamos descrever a construção de uma atividade investigativa com o Tema Gerador "A saúde" junto a uma turma do $6^{\circ}$ ano do Ensino Fundamental de uma escola agrícola do Estado do Espírito Santo que tem a "Pedagogia da Alternância"1

\footnotetext{
1 A Pedagogia da Alternância foi criada na França caracteriza-se por ser um método que organiza o processo de ensino-aprendizagem de forma alternada entre a propriedade familiar e a escola, integrando e interligando momentos de trabalho e estudo (NOSELLA, 2012).
} 
como princípio educativo. Com o intuito de pensarmos novas estratégias de processos de ensino e de aprendizagem no ensino de ciências, associamos a abordagem dos Temas Geradores $^{2}$ (FREIRE, 1983) já dotados pela escola com a estratégia didática do ensino de ciências por investigação (AZEVEDO, 2004; CARVALHO, 2013; CARVALHO, 2018; MUNFORD e LIMA, 2007; SÁ, LIMA e AGUIAR, 2011).

Inicialmente, como forma de contextualizar este campo de conhecimento, apresentamos brevemente os pressupostos teóricos da Educação do Campo, problematizando o ensino de Ciências e o ensino por investigação. A Educação do Campo tem em sua gênese o histórico de insatisfação com o modelo educacional tradicional de ensino e é fruto da resistência camponesa e da mobilização dos movimentos populares pelo direito coletivo a uma educação própria e apropriada para os sujeitos do campo. Este direito compreende o campo como local de produção e socialização de conhecimento e não mais um lugar de atraso, historicamente marginalizado, subjugado ao agronegócio (CALDART, 2005).

De acordo com a Resolução CNE/CEB 1, de 3 de abril de 2001, que institui as Diretrizes Operacionais para a Educação Básica nas Escolas do Campo, a identidade da escola do campo está vinculada a realidades das populações campesinas, incluindo os saberes próprios dos educandos ${ }^{3}$ e a memória coletiva das comunidades. A legislação também ressalta que essa identidade se embasa "[...] na rede de ciência e tecnologia disponível na sociedade e nos movimentos sociais em defesa de projetos que associem as soluções exigidas por essas questões à qualidade social da vida coletiva no país" (MEC, 2001, p. 1).

A Educação do Campo está associada ao modo de vida e ao trabalho no campo, e por consequência ao saber socialmente produzido neste meio. Dentro deste cenário,

\footnotetext{
2 Os temas geradores (FREIRE, 1983) surgem como uma abordagem de caráter histórico-social que possibilita aos sujeitos da ação educativa o protagonismo na seleção, organização e distribuição dos conhecimentos, promovendo a interdisciplinaridade e evitando a fragmentação do saber. Estes temas surgem após um processo sistemático de levantamento que parte de uma problemática da comunidade em que a escola se insere, envolvendo comunidade e escola.

${ }^{3}$ Adotamos ao longo deste artigo a denominação "educandos" ao invés de "alunos" em consonância com o referencial de Freire (1983).
} 
Freire (1983) propõe também a aproximação teórico-prática por meio da organização curricular a partir da realidade vivida pelo povo, com vistas em contribuir para a transformação da realidade social e para a solução de problemas de aspiração coletiva. Para o autor, a partir da conscientização os sujeitos são capazes de transformar sua realidade, por meio da ação -reflexão -ação.

Silva et al. (2019, p. 222) sobre o Ensino de Ciências no Campo, inferem que o ensino está intimamente ligado ao modo de vida das populações do campo, o que “implica na valorização da realidade em que os alunos estão inseridos, articulando os conteúdos com os saberes do campo em um movimento dialético de problematização e dialogicidade que envolva comunidade e escola”. Os mesmos autores, a partir de uma à análise de artigos publicados nos periódicos nacionais sobre Educação do Campo (Revista Brasileira de Educação do Campo, Revista Nera, Revista Extensão Rural e Revista Estudos Sociedade e Agricultura), utilizando uma abordagem qualitativa, no período entre 2007 a 2016, indicam a existência de uma lacuna relacionada a trabalhos direcionados ao Ensino de Ciências nas revistas de Educação do Campo, bem como poucas discussões com referenciais da área de Educação do Campo ou articulação entre o Ensino de Ciências e os saberes próprios do campo.

Baptista (2007; 2010) defende que o ensino de ciências em comunidades tradicionais deval ser baseado na valorização dos saberes científicos e dos saberes tradicionais, pois a oposição entre estes saberes pode induzir os educandos a conflitos entre as explicações científicas e os saberes de seus meios socioculturais. Essa dicotomia pode reforçar uma concepção de que a cultura científica escolar se torne uma “cultura estrangeira" para o educando. E neste sentido, Aikenhead (2009) aponta que é necessário que sejam criadas pontes culturais entre a cultura escolar em que o educando está inserido e a subcultura da ciência.

Além da cultura escolar e da subcultura da ciência, cada educando em seu meio de convivência participa de diversas outras subculturas, seja em sua família, comunidade, meios de interação e comunicação. Cada educando traz também consigo as vivências e experiências, assim, a valorização da subcultura da vida cotidiana de cada educando proporciona a construção dos conhecimentos escolares, mediante a sua contextualização em sua realidade (AIKENHEAD, 2009). 
Considerando as especificidades e características da Educação do Campo e as diversas subculturas presentes no cotidiano de cada educando, Rosa e Robaina (2020, p.158) afirmam que "se aliarmos esses conhecimentos prévios (dos educandos) e acrescentarmos aos saberes que a escola oferece, formaremos educandos pesquisadores, críticos, conscientes da sua realidade e ainda incentivaremos a curiosidade científica".

Neste contexto, o ensino por investigação, como abordagem didática para o ensino de ciências, aproxima a ciência acadêmica da ciência escolar, desenvolvendo o senso crítico, trabalhando não só questões ligadas ao currículo, mas também a racionalidade, os valores e questões morais. O ensino por investigação proporciona a construção do conhecimento, estimulando o educando a participar efetivamente do seu processo de ensino aprendizagem.

[...]utilizar atividades investigativas como ponto de partida para desenvolver a compreensão de conceitos é uma forma de levar o aluno a participar de seu processo de aprendizagem, sair de uma postura passiva e começar a perceber e agir sobre o seu objeto de estudo, relacionando o objeto com acontecimentos e buscando as causas dessa relação, procurando, portanto, uma explicação causal para o resultado de suas ações e/ou interações (AZEVEDO, 2004, p. 22).

O ensino por investigação configura-se como abordagem didática que envolve, inicialmente, situações problemas que estimulam os educandos a planejarem, questionarem, a produzir evidências, registrar, avaliar e comunicar as explicações, envolvendo-os na cultura científica de modo que possam desenvolver liberdade e autonomia intelectuais por meio de um ensino contextualizado (CARVALHO, 2013; SASSERON, 2015).

Sob a perspectiva do Ensino de Ciências por Investigação as aulas podem ser organizadas a partir de um tema ou conteúdo programático, seguindo etapas que integram uma Sequência de Ensino Investigativa (SEI) conforme defende Carvalho (2013). Essas etapas visam promover o diálogo, soluções para o problema inicial, surgimento de outros estudos, objetivando à apropriação do conhecimento sistematizado. Carvalho (2013, p. 7) propõe a SEIs, apontando que:

[...] as sequências de ensino investigativas (SEIs), isto é, sequências de atividades (aulas) abrangendo um tópico do programa escolar em que cada atividade é planejada, do ponto de vista do material e das interações didáticas, visando proporcionar aos alunos: condições de trazer seus conhecimentos prévios para iniciar os novos, terem ideias próprias e poder 
discuti-las com seus colegas e com o professor passando do conhecimento espontâneo ao científico e adquirindo condições de entenderem conhecimentos já estruturados por gerações anteriores (CARVALHO, 2013, p. 7).

As SEIs são compostas por "atividades-chave": (i) problematização: etapa inicial em que os educandos formulam um problema de investigação e que está ligado ao tema da aula; (ii) a sistematização do conhecimento construído: que acontece após a resolução do problema; (iii) contextualização do conhecimento: proposição de aplicação do conhecimento no dia a dia ou aprofundamento do assunto; (iv) avaliação: análise do processo de construção do conhecimento.

Tendo como pressupostos o modelo de Educação do Campo baseado na pedagogia da alternância e no trabalho com Temas Geradores, buscamos na abordagem didática do ensino de ciências por investigação um referencial que pudesse contribuir no desenvolvimento de uma atividade que aborda o Tema Gerador " A saúde”. Nesse contexto elaboramos a questão de investigação: como se desenvolveu uma atividade sobre plantas medicinais, realizada a partir de uma perspectiva do ensino de ciências por investigação?

\section{METODOLOGIA}

A pesquisa, de cunho qualitativo, teve como base a pesquisa participante (BRANDÃO, 1998) que se caracteriza como um modelo de investigação social, que tem como ponto de partida a realidade social, a vida concreta dos participantes como sujeitos históricos e sociais, propiciando o envolvimento destes na construção dos saberes na medida que eles atuam como co-pesquisadores.

A pesquisa foi desenvolvida com uma turma do $6^{\circ}$ ano do Ensino Fundamental de uma escola agrícola do Estado do Espírito Santo que funciona em regime da Pedagogia da Alternância e utilizou o Tema Gerador "A saúde" como elemento estruturador da atividade investigativa. A partir desse tema gerador, os educandos, em colaboração com a educadora, construíram um Plano de Estudo denominado "A Saúde e seus Problemas na Família". Este Plano de Estudo foi composto por um questionário em que os educandos fazem uma investigação atuando como co-pesquisadores junto a suas 
famílias, comunidade e região, o que proporciona o intercâmbio entre os saberes escolares e comunitários (DE BURGHGRAVE,2011, p.149).

No desenvolvimento desse Plano de Estudo houve o questionamento por parte dos educandos sobre as formas de tratamento convencionais e tradicionais e a necessidade de um aprofundamento de conteúdos relacionados a "medicina tradicional" baseada nos conhecimentos da tradição que são passados entre as gerações nas famílias e comunidades, especificamente sobre as plantas medicinais.

Nesta direção, elaboramos uma proposta de atividade baseada nas etapas de uma sequência de ensino investigativo - SEI (CARVALHO, 2013) que seguiu as seguintes etapas:

1- Problematização: esta etapa teve como base a formulação de questões de investigação sobre as formas de tratamento tradicionais, com ênfase na utilização de plantas medicinais, a serem aplicadas junto as famílias dos educandos. Assim, com auxílio da educadora mediadora (da disciplina de Ciências) os educandos elaboraram as seguintes questões de investigação:

1-Quais os tipos de plantas medicinais, óleos, extratos e outros remédios caseiros que a família usa como forma de tratamento dos problemas de saúde?

2-Quais partes das plantas a família utiliza?

3-Qual o "modo de fazer" esses remédios?

4-Quais os problemas de saúde que são tratados com remédios caseiros pela família?

5-Qual a opinião da família sobre o uso dos remédios caseiros para o tratamento de problemas de saúde?

Com base nestas perguntas os educandos entrevistaram seus familiares e comunidade acerca de seus conhecimentos tradicionais sobre as plantas medicinais registrando as respostas. Estas questões foram respondidas por famílias de 14 educandos que residiam em 7 comunidades vizinhas a escola durante o tempo comunidade.

2-Sistematização: A partir dos dados coletados, os educandos retornam a escola e realizam a análise e sistematização dos dados das entrevistas em colaboração com a 
educadora. Este processo aconteceu por meio da formação de grupos em que os educandos sintetizam suas repostas em uma única redação. A síntese final é digitada (pela educadora) e lida em sala.

3-Contextualização: Durante a leitura, os educandos e a educadora dialogam, problematizam e contextualizam as informações buscando verificar se ocorreram respostas para todas as indagações e se surgiram novas possibilidades de aprofundamento e estudos sobre o tema de modo a buscar a aplicação do conhecimento construído do ponto de vista social. Nesta fase, educadora e educandos avaliam a atividade.

A educadora da disciplina de Ciências atuou durante a atividade investigativa como professora e pesquisadora escutando e dialogando com os educandos desde a: (i) necessidade apontada por eles de um maior aprofundamento sobre os conhecimentos tradicionais acerca de medicamentos alternativos e plantas medicinais utilizados pelas famílias e comunidades; (ii) elaboração e seleção dos questionamentos; (iii) acompanhamento das entrevistas realizada por eles junto as famílias. Durante estas etapas, a educadora atuou na direção de fomentar o desenvolvimento de habilidades como a autonomia, a capacidade de tomada de decisão, de avaliação e de resolução de problemas, características de atividades baseadas no Ensino de Ciências por Investigação (SÁ, LIMA e AGUIAR JR.,2011).

O processo de produção de dados aconteceu por meio de observações da professora pesquisadora com registro em diário de campo e material escrito produzido pelos estudantes.

Os dados foram analisados a partir dos pressupostos do ensino de ciências por investigação que direcionam uma SEI: problematização, sistematização e contextualização do conhecimento.

\section{RESULTADOS E DISCUSSÃO}

Para fins de análise, delimitamos dois eixos baseados nos pressupostos e etapas de uma SEI: (i) Fase de problematização: elaboração de questões de investigação; (ii) Fase de Sistematização e contextualização: síntese produzida na interação.

3.1 Fase de problematização: elaboração de questões de investigação 
Segundo Carvalho (2013), a SEI possui alguns momentos chave que tem início com uma fase de problematização do conhecimento. Este processo teve início a partir do desenvolvimento inicial do Tema Gerador "A saúde" e que culminou com a elaboração de um questionário contendo questões de investigação a partir dos estudos já realizados pelos educandos visando um maior aprofundamento sobre os conhecimentos tradicionais acerca de medicamentos alternativos utilizados pelas famílias e comunidades (plantas medicinais).

As perguntas formuladas ocorreram no período do tempo-escola (conforme acontece na pedagogia da alternância) e tiveram como base os conhecimentos prévios dos educandos e os conhecimentos construídos por eles anteriormente na realização do Plano de Estudo. Na elaboração das perguntas observamos um grande envolvimento dos educandos que se materializou por meio do interesse e da curiosidade pela temática a ser estudada. Ao problematizarem a realidade, as perguntas elaboradas adquirem sentido e significado para estes educandos.

Segundo Freire e Faundez (1985, p.46) "[...] o que o professor deveria ensinar porque ele próprio deveria sabê-lo seria, antes de tudo, ensinar a perguntar. Porque o início do conhecimento, repito, é perguntar". Neste sentido, quando os educandos se engajam em formular perguntas, o modelo educacional tradicional de ensino em que as respostas vêm prontas cai por terra. Sob uma dimensão social e política a pergunta se constitui como um recurso democratizante do processo ensino aprendizagem, rompendo também, de um modo mais amplo, com as relações de poder dentro da sala de aula. Dessa forma, relações dialógicas são estabelecidas.

Nesta linha de raciocínio, o ensino de ciências por investigação, tem como pressuposto a problematização da realidade, a formulação de questões problema que engajem o educando no fazer ciência. Ao elaborarem o questionário, os educandos desempenham papel ativo na construção e no entendimento do processo científico, elaborando e selecionando questões sobre tópicos que eles julgavam necessários para sanar as dúvidas da pesquisa sobre as plantas medicinais e seus usos (SASSERON,2015). 
Neste questionário observamos que as quatro primeiras perguntas foram motivadas pelo interesse em fatos concretos: quais as plantas medicinais utilizadas? Quais as partes são utilizadas? Para que eram usadas (utilidade)? E de que modo eram feitos os remédios caseiros? Observa-se a articulação entre as questões no intuito de aprofundar o conhecimento e conhecer os processos.

$\mathrm{Na}$ questão 5, os educandos questionam as famílias sobre a sua opinião a respeito do uso dos remédios caseiros para o tratamento de problemas de saúde e aqui podemos observar o olhar reflexivo dos educandos ao questionar o posicionamento das famílias sobre o uso das plantas medicinais.

Segundo Carvalho (2013), o processo de construção da problematização é fundamental no desenvolvimento de uma atividade investigativa, pois é partir desse processo que os educandos adquirem motivação para levarem a investigação adiante. Neste caso, o fato dos educandos terem sido protagonistas na elaboração da problematização, na proposição de formas para responder as perguntas dentro de seu domínio e da realidade foi fundamental. Dentro desse contexto, Brandão e Borges (2007, p. 08) argumentam que "[...]a participação popular comunitária deve se dar, através de todo o processo de investigação-educação-ação", não existindo imposição e sim a criação solidária do conhecimento".

\subsection{Fase de Sistematização e contextualização: síntese produzida na interação}

Após a fase de problematização, inicia-se a sistematização do conhecimento que ocorreu por meio da interação da educadora com os educandos (na escola) para a produção de uma síntese que se materializou por meio de um texto escrito. Este processo interativo forneceu as condições para que os estudantes pudessem colocar em diálogo os dados produzidos e ao mesmo tempo realizar a contextualização do

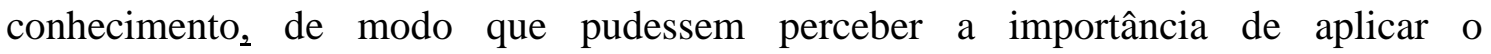
conhecimento no dia a dia e até propor um maior aprofundamento do assunto.

Durante o primeiro momento, os educandos estabeleceram discussões com seus grupos para elaboração de uma pré-síntese a partir das respostas obtidas nos questionários comunicando seus dados de forma escrita. Posteriormente, as pré-sínteses 
dos grupos são reunidas na síntese final que é digitada pela educadora, entregue aos educandos, lida e discutida em sala.

$\mathrm{Na}$ interação, os educandos se envolvem na sistematização dos dados de forma ativa, participando da construção do conhecimento. Esta atitude de envolvimento dos estudantes na resolução das questões é apontada por autores como Carvalho (2013) como um pressuposto fundamental no ensino por investigação e se materializa quando o estudante tem liberdade intelectual para se expressar. Nesta mesma direção, Freire (1996) ressalta a importância de o educando desempenhar papel de sujeito ativo na interação dos processos de ensino aprendizagem.

No processo de sistematização, as respostas foram reunidas na seguinte síntese:

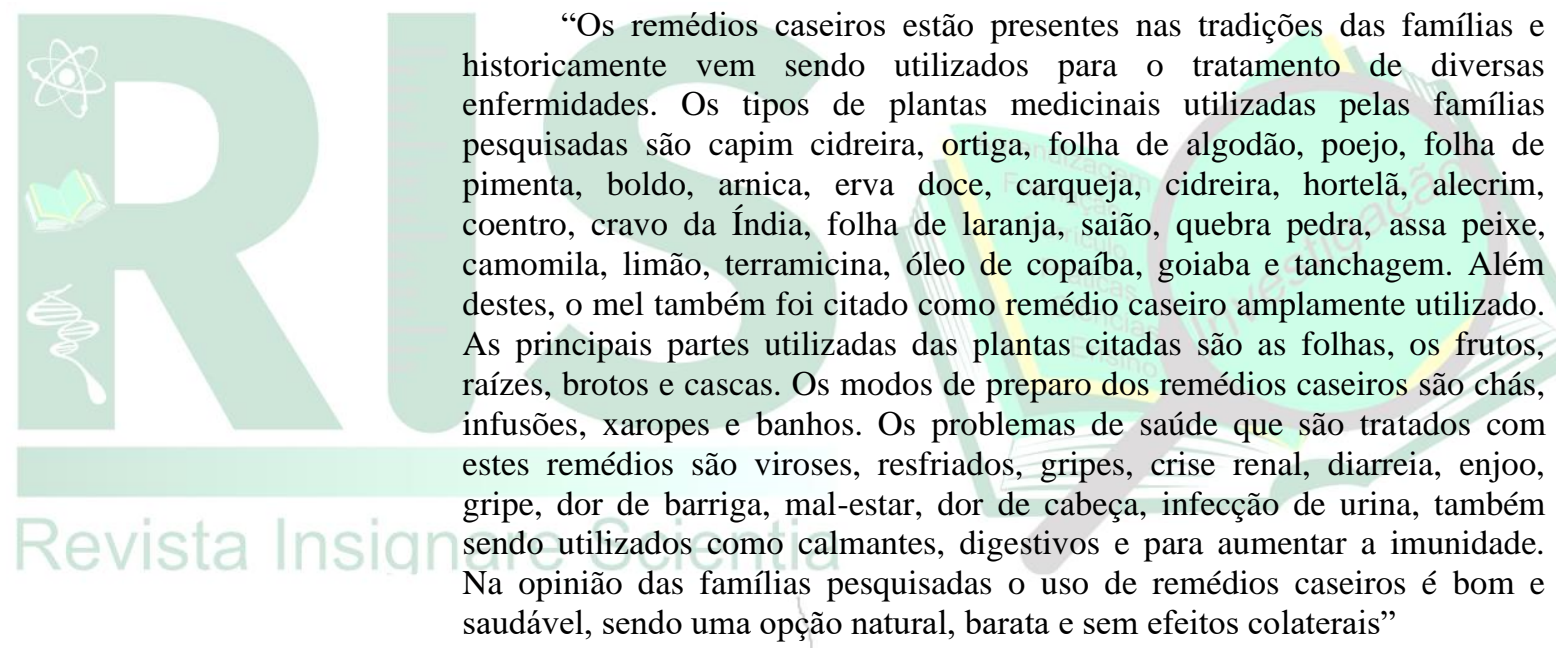

A partir da síntese os educandos compreendem que as famílias historicamente utilizam remédios caseiros com base na medicina tradicional por meio do uso de plantas medicinais para o tratamento de enfermidades fazendo um resgate dos conhecimentos tradicionais de suas famílias e comunidades. Os educandos identificaram as principais plantas medicinais utilizadas pelas famílias como por exemplo o capim cidreira, ortiga, folha de algodão e o poejo. As partes das plantas mais utilizadas foram as folhas, os frutos, raízes, brotos e cascas. Com relação aos modos de preparo dos remédios os educandos identificaram os chás, infusões, xaropes e banhos. Os problemas de saúde que podem ser tratados por meio destas plantas foram: viroses, resfriados, gripes, crise 
renal, diarreia, enjoo, gripe, dor de barriga, mal-estar, dor de cabeça, infecção de urina, calmantes, digestivos e problemas de imunidade.

Azevedo (2004); Lima e Maués (2006) afirmam que os alunos que são colocados em processos investigativos deixam de desempenhar papéis passivos de meros receptores de informação, se envolvem com a sua aprendizagem e desenvolvem habilidades da cultura científica: problematizam, levantam hipóteses, produzem dados, analisam evidências, argumentam, sistematizam, descrevem e comunicam os seus resultados.

Durante o desenvolvimento da atividade investigativa podemos destacar o papel do educador no planejamento e desenvolvimento da atividade criando junto aos educandos diversas possibilidades para que estes pensem, estruturem seu conhecimento, argumentem, articulem, leiam e entendam o conteúdo atuando como protagonistas na construção do saber. Freire (1996) ressalta a importância do processo de produção, construção e sistematização do conhecimento entre educador e educando em uma prática problematizadora e dialógica no qual ambos crescem juntos como sujeitos no percurso.

A contextualização dos dados produzidos se deu a medida em que os educandos trouxeram a importância de resgate do saber tradicional sobre plantas medicinais para dentro da escola, valorizando o modo de vida do Campo e reconhecendo este saber como fonte de produção de conhecimento. Por meio de momentos de compartilhamento de práticas e experiências das diferentes famílias e comunidades foi proporcionado aos educandos novos aprendizados que poderão servir como fonte para inovações relacionadas a ciência como a importância da conservação do patrimônio genético dessas plantas, novas utilizações na alimentação, e na proteção e o acesso ao conhecimento tradicional (BRASIL, 2007).

\section{CONSIDERAÇÕES FINAIS}

Consideramos que a construção da atividade investigativa com o Tema Gerador "A saúde" contribuiu para a construção coletiva do conhecimento sobre as plantas medicinais. A atividade promoveu a autonomia e o protagonismo dos educandos durante o processo de investigação quando os educandos trabalharam: (i) na elaboração 
das questões a serem investigadas; (ii) na produção, sistematização e análise dos dados; (iii) e na comunicação dos resultados. Além disso, observamos o desenvolvimento de habilidades como organização de equipes, capacidade de trabalho em grupo e avaliação coletiva do processo que evidenciam uma postura ativa e crítica dos educandos que é de fundamental importância em atividades e processos de pesquisa científica.

Ao abordar a temática das plantas medicinais por meio do ensino de ciências por investigação os educandos promoveram o resgate e a valorização dos saberes tradicionais que são repassados através das gerações e que poderiam ser perdidos. Esta valorização reforça um dos pressupostos teóricos para a Educação do Campo que é uma educação comprometida com as questões do campo e que é defendida por Arroyo (2005, p. 45) “[...] é possível resgatar uma proposta pedagógica, buscando recuperar o saber, a cultura, a ética, recuperar os valores próprios de uma educação básica para o campo[...]" sendo traduzido no "[...] direito ao saber, direito ao conhecimento e a cultura produzida socialmente".

\section{REFERENCIAS}

AIKENHEAD, G. S. Educação científica para todos. Tradução de Maria Teresa Oliveira. Mangualde, Portugal: Edições Pedagogo, 2009.

ARROYO, M. G. A educação básica e o movimento social do campo. In: ARROYO, Miguel Gonzalez; CALDART, Roseli Salete; MOLINA, Mônica Castagna (Org.). Por uma educação do campo. 3. ed. Petrópolis, RJ: Vozes, 2008. Cap. 2.

AZEVEDO, M. C. P. S. de. Ensino por investigação: problematizando as atividades em sala de aula. In: CARVALHO, A. M. P. de. (Org.). Ensino de ciências: unindo a pesquisa e a prática. São Paulo: Pioneira Thomson Learning, 2004. p.19-33.

BAPTISTA, G. C. S. B. Importância da demarcação de saberes no ensino de ciências para sociedades tradicionais. Ciência \& Educação, v. 16, n. 3, p. 679-694, 2010.

BAPTISTA, G. C. S. A contribuição da etnobiologia para o ensino e a aprendizagem de ciências: estudo de caso em uma escola pública do estado da Bahia. 2007. 188f. Dissertação (Mestrado em Ensino, Filosofia e História das Ciências) Universidade Federal da Bahia, Salvador, 2007.

BRANDÃO, C. R. ; BORGES, M. C. A pesquisa participante: um momento da educação popular. Rev. Ed. Popular, Uberlândia, v. 6, p.51-62. jan./dez. 2007.

BRANDÃO, C. R. Participar-pesquisar. In: Brandão, Carlos Rodrigues (org). Repensando a pesquisa participante. 3 ed. São Paulo: Brasiliense, 1998.

BRASIL. Conselho Nacional de Educação (CNE). Câmara de Educação Básica (CEB). Parecer CNB/CEB no 36/2001: Diretrizes Operacionais para a Educação Básica nas Escolas do Campo. Brasília: CNE, 4 de dezembro de 2001. 
BRASIL. Ministério da Educação. Conselho Nacional de Educação. Comissão de Educação Básica. Resolução n.1 de 03 de abril de 2002, estabelece Diretrizes para a Educação Básica nas escolas do campo, publicada no Diário Oficial da União. Brasília-DF: Gráfica do Senado, em 09 de abril de 2002.

BRASIL. Decreto $\mathbf{n}^{\mathbf{0}}$ 6.040, de 07 de fevereiro de 2007. Institui a Política Nacional de Desenvolvimento Sustentável dos Povos e Comunidades Tradicionais. Brasília, 7 de fevereiro de 2007. Disponível em: < http://www.planalto.gov.br/ccivil_03/_ato20072010/2007/decreto/d6040.htm>. Acesso em: 10 jan. 2020.

CALDART, R. S. Elementos para a construção do Projeto Político e Pedagógico da Educação do Campo. In: PARANÁ. Secretaria de Estado da Educação. Cadernos temáticos: educação do campo. Curitiba, SEED, 2005. p. 23-34.

CARVAlHO, A. M. P. Fundamentos Teóricos e Metodológicos do Ensino por Investigação. Revista Brasileira de Pesquisa em Educação em Ciências, v. 18, n. 3, p. 765-794, 2018.

CARVAlHO, A. M. P. de. O ensino de Ciências e a proposição de sequências de ensino investigativas. In CARVALHO, Anna Maria Pessoa de (Org.), Ensino de Ciências por Investigação: condições para implementação em sala de aula. São Paulo: Editora Cengage Learning. p. 1-20, 2013.

DE BURGHGRAVE. T. Vagabundos, não senhor Cidadãos brasileiros e planetários: uma experiência educativa pioneira do Campo. Orizona / GO: UNEFAB, 2011.

FREIRE, P. Pedagogia do oprimido. São Paulo: Paz e terra, 1983.

FREIRE, P.; FAUNDEZ, A. Por uma pedagogia da pergunta. Rio de Janeiro: Paz e Terra, 1985.

FREIRE, P. Pedagogia da autonomia: Saberes necessários a prática educativa. $25^{\text {a }}$ ed São Paulo: Paz e Terra, 1996.

LIMA, M.E.C.C.; MAUÉS, E. Uma releitura do papel da professora das séries iniciais no desenvolvimento e aprendizagem de ciências das crianças. Revista Ensaio. V. 8. n.2. 2006.

MUNFORD, D.; LIMA, M. E. C. C. Ensinar ciências por investigação: em quê estamos de acordo? Revista Ensaio: Pesquisa em Educação em Ciências. Belo Horizonte, v. 9, n. 1, p. 72-89, 2007.

NOSELLA, Paolo. Origens da Pedagogia da Alternância no Brasil. Vitória, EDUFES, 2012.

ROSA, S.S. da; ROBAINA, J. V. L. O Ensino de Ciências nas Escolas do Campo a partir da análise da produção acadêmica. Revista Insignare Scientia. Vol. 3, n. 2. Mai./Ago.2020.

SÁ, E. F.; LIMA, M. E. C. C.; AGUIAR JUNIOR, O. A construção de sentidos para o termo Ensino por Investigação no contexto de um curso de formação. Investigações em Ensino de Ciências. v. 16, n. 1, p. 79-102, 2011. 
SILVA et al. Educação do campo e ensino de ciências no Brasil: uma revisão dos últimos dez anos. R. bras. Ens. Ci. Tecnol., Ponta Grossa, v. 12, n. 1, p. 221-239, jan. labr. 2019.

SASSERON, L. H. Alfabetização científica, ensino por investigação e argumentação: relações entre ciências da natureza e escola. Revista Ensaio. Belo Horizonte. v.17 n. especial, p. 49-67, nov. 2015. 